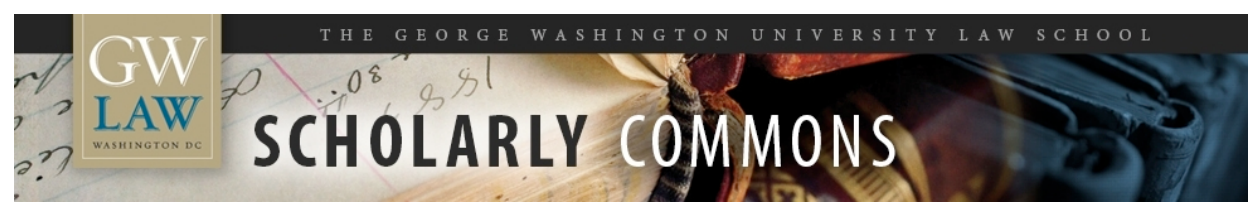

\title{
The Future of Nanotechnology Risk Perceptions: An Experimental Investigation of Two Hypotheses
}

\author{
Donald Braman \\ George Washington University Law School, dbraman@law.gwu.edu \\ Dan M. Kahan \\ Paul Slovic \\ John Gastil \\ Geoffrey L. Cohen
}

Follow this and additional works at: https://scholarship.law.gwu.edu/faculty_publications

Part of the Law Commons

\section{Recommended Citation}

Braman, Donald; Kahan, Dan M.; Slovic, Paul; Gastil, John; and Cohen, Geoffrey L., "The Future of Nanotechnology Risk Perceptions: An Experimental Investigation of Two Hypotheses" (2008). GW Law Faculty Publications \& Other Works. 198.

https://scholarship.law.gwu.edu/faculty_publications/198

This Article is brought to you for free and open access by the Faculty Scholarship at Scholarly Commons. It has been accepted for inclusion in GW Law Faculty Publications \& Other Works by an authorized administrator of Scholarly Commons. For more information, please contact spagel@law.gwu.edu. 


\section{The Future of Nanotechnology Risk Perceptions: An Experimental Investigation of Two Hypotheses}

\author{
Dan M. Kahan \\ Yale Law School
}

\author{
Donald Braman \\ George Washington \\ Law School
}

\author{
Paul Slovic \\ Decision Research
}

\author{
John Gastil \\ University of Washington
}

\author{
Geoffrey Cohen \\ University of Colorado
}

This paper reports the results of an experiment designed to test competing conjectures about the evolution of public attitudes toward nanotechnology. The "rational enlightenment" hypothesis holds that members of the public will become favorably disposed to nanotechnology as balanced and accurate information about it disseminates. The "cultural cognition" hypothesis, in contrast, holds that members of the public are likely to polarize along cultural lines when exposed to such information. Using a between-subjects design $(N=1,862)$, the experiment compared the perceptions of subjects exposed to balanced information on the risks and benefits of nanotechnology to the perceptions of subjects exposed to no information. The results strongly confirmed the cultural polarization hypothesis and furnished no support for the rational enlightenment hypothesis. Data obtained in the experiment also suggested that the observed correlation in the general public between familiarity with nanotechnology and a positive view of it is spurious: familiarity does not cause a favorable view; rather other influences, including individualistic cultural values, incline certain individuals both to form a positive view and to learn about nanotechnology. The paper also discusses the implications of these findings for promoting informed public understandings of nanotechnology.

Research for this article was supported by the National Science Foundation, Grant SES 0621840; the Project on Emerging Nanotechnologies Woodrow Wilson International Center for Scholars; and by the Oscar Ruebhausen Fund at Yale Law School. 


\section{The Future of Nanotechnology Risk Perceptions: An Experimental Investigation of Two Hypotheses}

\author{
Dan M. Kahan
}

Yale Law School

\author{
Donald Braman \\ George Washington \\ Law School
}

\author{
Paul Slovic \\ Decision Research
}

\author{
John Gastil \\ University of Washington
}

\author{
Geoffrey Cohen \\ University of Colorado
}

\section{Introduction}

Its immense range of potential applications-scientific, commercial, medical, and more-marks nanotechnology as one of the most promising new forms of applied science. The future of nanotechnology, however, will depend not just on anticipation of its likely benefits but also on concern about its possible risks. Most members of the public have heard little or nothing about nanotechnology. Should they react with fear as they learn more, regulators applying the "precautionary principle" (Sunstein, 2005) might well be disposed to enact restrictions that delay its development or even stifle investment in this nascent science.

How is public opinion toward nanotechnology likely to evolve? Does the answer depend on what future study reveals about the risks and benefits of nanotechnology? Or will other influences-ones that operate independently of the best available scientific information-play a decisive role?

There have been numerous survey-based studies of public attitudes toward nanotechnology. Most find the public has a modestly positive view of nanotechnology (Currall, Kind, Lane, Madera \& Turner 2006; Scheufele, Corley, Dunwoody, Shih, Hillback, Elliott, Guston, 2007), and that those who know the most are in fact the most favorably disposed toward it (Cobb \& Macoubrie 2004; Hart 2006, 2007; Scheufele \& Lowenstein 2005).

Although such studies are extremely valuable, what we can deduce from them is limited by their methodology. Because they are surveys and not ex- 
periments, these studies do not tell us tell how uninformed members of the public are likely to react as they learn more. Likewise, they cannot tell us whether relatively well informed members of the public are positively disposed because they have learned more about nanotechnology or instead whether they have chosen to learn more because they are positively disposed toward nanotechnology for some other reason.

This paper reports the result of an experiment aimed at addressing those issues. The experiment involved comparing the perceptions of individuals who received no information on nanotechnology to those of individuals we exposed to balanced information on its risks and benefits. We found that relative to the uninformed subjects, subjects exposed to information polarized along various lines, including cultural predispositions toward environmental and technological risks generally. We also found that the correlation between level of knowledge toward nanotechnology and a positive assessment of nanotechnology was spurious. That is, rather than familiarity with nanotechnology causing subjects to view the benefits of nanotechnology as outweighing its risks, a third influence-likely a pro-technology, cultural predisposition-was causing both.

These findings are consistent with a growing body of research on the influence of cultural values on cognition of risk (Kahan, Slovic, Braman \& Gastil 2006). They imply that it would be a mistake to assume that public perceptions of nanotechnology risks will necessarily move in the direction of the best available scientific data. But at the same time, they suggest how those interested in the formation of informed public opinion should proceed to maximize the likelihood that the best scientific understandings will gain public acceptance.

Subsequent sections of the paper fill out these claims. Section 2 presents the theoretical and practical motivation behind the study in the form of two competing hypotheses about the formation of public attitudes toward nanotechnology. Section 3 describes the design of the study, and Section 4 its results. Finally, Section 5 concludes with a discussion of the implications of the study findings both for future research on nanotechnology risk perceptions and for the development of strategies for promoting informed public. 


\section{Two Hypotheses: Rational Enlightenment vs. Cultural Cognition}

How might the American public, which is currently knows little about nanotechnology, respond to information about it? We'll describe two competing answers. One can be called the "rational enlightenment" hypothesis, the other the "cultural cognition" hypothesis.

The rational enlightenment hypothesis holds, essentially, that members of the public can be expected to form positive attitudes toward nanotechnology as they learn more. The basis for the hypothesis is existing public opinion research. That research shows that very few members of the public have heard about nanotechnology, but that those who say they have heard about it believe that its benefits are likely to far outweigh its risks. Extrapolating, proponents of the rational enlightenment hypothesis infer that as more people are exposed to information about nanotechnology, they will form similarly positive assessments as well, at least so long as media coverage remains balanced and informed by accurate science (Cobb \& Macourbie 2004; Hart 2006, 2007; Currall, Kind, Lane, Madera \& Turner 2006; Scheufele, Corley, Dunwoody, Shih, Hillback, Elliott, Guston, 2007).

There are a number of reasons, however, to be skeptical about the rational enlightenment hypothesis. One is selection bias. Again, relatively few members of the public have heard about nanotechnology at this point; in some polls, $80 \%$ report that they have heard either "little" or "nothing at all" about it. The $20 \%$ or so, then, who say they have heard either a modest amount or a great deal about nanotechnology are doing something unusual: attaining information about this novel science. Maybe the same set of forces that are disposing these particular people to learn about nanotechnology before others do is also disposing them to form positive views about it. If so, one cannot reliably generalize from them to the public at large in assessing the impact of information on attitudes toward nanotechnology.

Another reason to be skeptical of the rational enlightenment hypothesis is a lesson taught by the study of public risk perceptions generally. It is that members of the public do not tend to react in a uniform way, much less in a uniformly positive way, to information about risk. Instead they act in disparate ways depending on various individual characteristics (Slovic 2000). 
Among the characteristics that matter a lot, research has shown, are individuals' basic values, or cultural orientations. ${ }^{1}$ The phenomenon of "cultural cognition" refers to the tendency of persons to conform their factual beliefs about the risks and benefits of a putatively dangerous activity to their cultural appraisals of these activities (DiMaggio 1997; Kahan, Slovic, Braman \& Gastil 2006). Basically, it is much easier, from a psychological point of view, to believe that behavior one finds noble is also socially beneficial, and behavior one finds debased is dangerous, than vice versa. This dynamic has been shown to lead people of diverse cultural outlooks to polarize as they react to information on various risks-from global warming to domestic terrorism, from school shootings to mandatory vaccination of school girls against HPV (Cultural Cognition Project 2007b).

Why should we expect the situation to turn out differently in the case of nanotechnology? The second hypothesis about the evolution of public attitudes toward nanotechnology-the cultural cognition hypothesis-is that it will not. In the normal course, people will tend to polarize along cultural lines.

Adapting a framework from Douglas (1970), studies of the cultural cognition of risk characterizes cultural worldviews, or preferences for how society should be organized, along two cross-cutting dimensions: "individualismcommunitarianism" and "hierarchy-egalitarianism." Persons holding individualistic worldviews tend to be dismissive of environmental and technological risks because they perceive (subconsciously) that crediting them would justify restraining markets and other kinds of private orderings that people with individualistic values like. Individuals holding hierarchal preferences react similarly because they associate assertions of environmental and technological risk with challenges to societal and governmental elites. Persons who are relatively egalitarian in outlook, in contrast, tend to embrace technological risk claims because doing so is congenial to their resentment of commerce and industry as activities that generate inequality. Those of a communitarian disposition, too,

1 There are numerous studies, including: Dake (1991); Ellis \& Thompson (1997); Gyawali (1999); Jenkins-Smith (2001); Kahan, Braman, Gastil, Slovic \& Mertz (2007); Marris, Langford \& Langford O'Riordan (1998); Peters, Burraston \& Mertz (2004); Peters \& Slovic (1996); Steg \& Sievers (2000); Poortinga, Steg \& Vlec (2002; Wildavsky \& Dake (1990). 
are relatively risk-sensitive, because they view business and industry as symbols of the pursuit of unconstrained self-interest. Such tendencies are particularly pronounced among persons holding combinations (hierarchical and individualistic, egalitarian and communitarian) of these values (Kahan et. al 2007).

With respect to nanotechnology, then, the cultural cognition hypothesis holds that as individuals learn more about nanotechnology they will form risk perceptions that reflect the dispositions toward environmental risk associated with their worldviews. Absent some calculated effort to frame information in a manner that makes nanotechnology appealing to persons of diverse values, individuals who hold relative egalitarian and communitarian worldviews will perceive nanotechnology to be dangerous, while those who hold relatively hierarchal and individualist worldviews will perceive it to be safe, as people with these dispositions learn more about this novel science.

\section{Experimental Study Design}

\subsection{Overview}

We designed an experiment to test the rational enlightenment and cultural cognition hypotheses. That design (explained in more detail below) involved comparing the risk perceptions of subjects whom we exposed to balanced information on nanotechnology to those whom we did not expose to such information.

The rationale for dividing the subjects into two groups was to facilitate a valid assessment of the effect of information. The Hart surveys $(2006,2007)$ had evaluated the impact of information by measuring the nanotechnology risk perceptions of one group of subjects before and after they received information. In such a design, changes in responses could be thought to reflect a contrived disposition on the part of subjects to appear open-minded and receptive to information. By comparing responses of two separate groups of subjects-one of whose members received information and another whose members did notour between-subjects design avoided this confounding explanation for any change in views.

The two hypotheses generate different predictions about the impact of information exposure. If the rational enlightenment experiment is correct, one 
would expect subjects exposed to information, particularly those who previously had little or no familiarity with nanotechnology, to form views more positive than those held by the subjects not exposed to information. The cultural cognition hypothesis, in contrast, implies that relative to subjects not exposed to information, subjects exposed to such information will react disparatelysome more positively, some more negatively-depending on their cultural worldviews. The design of the experiment thus called for various measures that would enable detection of such effects.

\subsection{Sample}

The sample consisted of a diverse sample of approximately 1,850 subjects demographically weighted to reflect national representativeness. They were drawn randomly from a panel of approximately 40,000 individuals recruited by Knowledge Networks for participation in scholarly public opinion analysis. ${ }^{2}$ The subjects were administered an on-line survey-experiment that consisted of approximately 50 questions and that took an average of approximately 10 minutes to complete. ${ }^{3}$ Survey responses were collected between December 14, 2006, and December 28, 2006.

\subsection{Experimental Manipulation: Information Exposure}

As indicated, subjects were divided into two groups. The "no information treatment" group was exposed to no information about nanotechnology aside from a minimal introductory statement:

Now we would like to know what you think about nanotechnology. Nanotechnology is the ability to measure, see, predict and make things on the extremely small scale of atoms and molecules. Materials created with nanotechnology can often be made to exhibit very different physical, chemical, and biological properties than their normal size counterparts.

This brief and nonjudgmental language, adapted from Hart (2006), was included with the expectation that without at least a minimal description of nanotechnology subject who indicated lack of prior familiarity with nanotech-

\footnotetext{
2 A more complete description of the composition of Knowledge Networks and of the demographic characteristics of the sample used in this study appears in Appendix A.

3 Pertinent elements of the survey instrument appear in Appendix B.
} 
nology would feel it was inappropriate to respond to items soliciting their attitudes toward it even if they had an opinion on nanotechnology's relative risks and benefits.

The "information treatment" group received the introductory statement plus two additional paragraphs. Also adapted from Hart (2006), the paragraphs (the order of which was randomly varied) related, respectively, to the benefits and risks of nanotechnology:

The potential benefits of nanotechnology include the use of nanomaterials in products to make them stronger, lighter and more effective. Some examples are food containers that kill bacteria, stain-resistant clothing, high performance sporting goods, faster, smaller computers, and more effective skincare products and sunscreens. Nanotechnology also has the potential to provide new and better ways to treat disease, clean up the environment, enhance national security, and provide cheaper energy.

While there has not been conclusive research on the potential risks of nanotechnology, there are concerns that some of the same properties that make nanomaterials useful might make them harmful. It is thought that some nanomaterials may be harmful to humans if they are breathed in and might cause harm to the environment. There are also concerns that invisible, nanotechnology-based monitoring devices could pose a threat to national security and personal privacy.

The sizes of the two groups differed: approximately 1,500 for the noinformation treatment group and approximately 350 for the informationtreatment group. The larger sample size for the no-information group was selected in order to permit confident generalizations from subject responses to attitudes in the American public at large. ${ }^{4}$ The smaller sample used for the information-treatment group was anticipated to be large enough to permit detection of the hypothesized cultural polarization effects across subjects of diverse cultural orientations and other characteristics.

\footnotetext{
4 Additional findings relating to public opinion on nanotechnology generally are described in greater detail in a report prepared for the Project on Emerging Nanotechnology (Cultural Cognition Project 2007a).
} 


\subsection{Measures}

\subsubsection{Cultural Worldviews}

The subjects' cultural worldviews were measured with two scales developed for use in a previous national study of cultural orientations and risk perceptions (Kahan, Braman, Gastil, Slovic \& Mertz 2006). "HierarchyEgalitarianism" ("Hierarchy") consisted of 12 items, and "IndividualismCommunitarianism" ("Individualism") 18 items, designed to assess subjects' worldviews along those two dimensions. Both were highly reliable (Hierarchy, $\alpha$ $=.81$; Individualism $\alpha=.83$ ). Based on their scores relative to the median ones for Hierarchy and Individualism, individuals were designated as either "Hierarchs" or "Egalitarians," and as either "Individualists" or "Communitarians." They were further divided into four distinct types- "Hierarchical Individualists," "Hierarchical Communitarians," "Egalitarian Individualists, and "Egalitarian Communitarians"-based on their scores relative to the means on both scales.

\subsubsection{Other Individual Characteristics}

Various demographic characteristics of interest were collected. These included the subjects' races, their genders, their ages, their education levels, their household incomes, their political party affiliations, and their political ideologies (measured with a liberal-conservative scale).

\subsubsection{Nanotechnology}

The experiment-survey instrument contained a number of items relating to nanotechnology. One ("Nanoknow"), used in previous studies (Hart 2006, 2007; Cobb \& Macoubrie 2004) asked "[h]ow much have you heard about nanotechnology before today?": "nothing at all," "just a little," "some," and "a lot." 5 Subjects who indicated they had heard "nothing at all" or "just a little"

\footnotetext{
5 Subjects were instructed that they should refuse to answer this or any other question on which they were "unsure." This instruction has been found to generate the same rate of "don't know/unsure" responses among on-line survey respondents as permitting only a volunteered "don't know/unsure" response in telephone surveys (Dennis, Li, \& Chatt 2004).
} 
were classified as being "unfamiliar" with nanotechnology, those who had heard "some" or "a lot" as "familiar" with it.

Finally, subjects' perceptions of nanotechnology risks was measured with an item ("Nanorisk") that asked them "[d]o you think the risks of nanotechnology will greatly outweigh its benefits, the risks of nanotechnology will slightly outweigh its benefits, the benefits of nanotechnology will slightly outweigh its risks[,] [or] the benefits of nanotechnology will greatly outweigh its risks[?]" Subjects responded to this item after reading the introductory statement and, in the case of the information-treatment group, the balanced-information paragraphs. Response were treated as forming a four-point scale (reverse coded) to asses mean nanotechnology risk perceptions across cultural and other groups of interest.

\subsubsection{Other Risk Perceptions}

We also collected data on subjects' perceptions of various other societal risks. Subjects were asked to indicate how much risk each of a diverse set of conditions and activities posed "to the safety or health of people in our society" using a four-point scale ( 1 = "almost no risk"; 2 = "slight risk"; 3 = "moderate risk"; and 4 = "high risk").

\section{Results}

\subsection{Generalized Risk-Insensitivity of Subjects Familiar with Nanotechnology}

Within the no-information treatment, we found (consistent with Cobb \& Macoubrie 2004; Hart 2006, 2007), a correlation between familiarity with nanotechnology and perceptions of its risks and benefits. The vast majority of these subjects-over $80 \%$ - had heard either "a little" or "nothing at all" about nanotechnology before the study (Figure 1). Among the relatively small group of subjects familiar with nanotechnology-the ones who said they had previously heard either "some" or "a lot" about it-81\% said they believed that the risks would outweigh the benefits, and only $17 \%$ that the benefits would outweigh the risks. Among the much larger group who were relatively unfamiliarthose who said they had heard either "little" or "nothing" about nanotechnol- 
ogy- $-47 \%$ said that the benefits would outweigh the risks, and $40 \%$ that the risks would outweigh the benefits (Table 1).

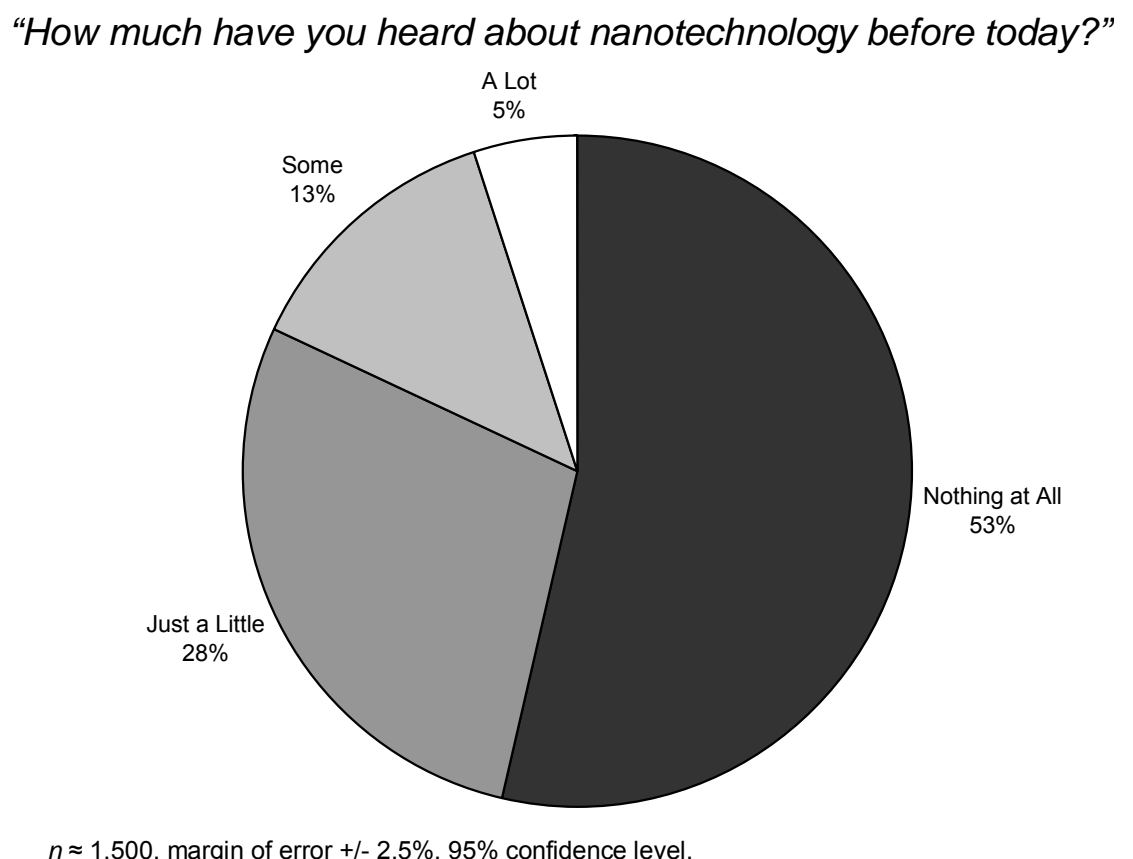

Figure 1. Familiarity with Nanotechnology

\begin{tabular}{lccc} 
& Benefit $>$ Risk & Risk $>$ Benefit & Unsure \\
\cline { 2 - 4 } Overall & $53 \%$ & $36 \%$ & $11 \%$ \\
\hline Familiar & $81 \%$ & $17 \%$ & $2 \%$ \\
Unfamiliar & $47 \%$ & $40 \%$ & $13 \%$ \\
\hline
\end{tabular}

$n \approx 1,500 . \pm 2.5 \%$ at $95 \%$ confidence interval.

Table 1. Perceptions of Nanotechnology Based on Familiarity (No-Information Treatment)

Interestingly, however, there was also significant correlation between familiarity with nanotechnology and societal risk perceptions generally (Figure 2). Obviously, these correlations are spurious. People who are familiar with nanotechnology are generally insensitive to a wide range of risk; it is not at all plausible, however, to think that their familiarity with nanotechnology is the reason they are relatively unworried about private gun ownership, mad cow disease, nuclear power, genetically modified food, the internet, pornography, and gay marriage. It is much more likely that some third variable explains both these individuals' lack of concern with these risks and their disposition to learn something about nanotechnology. 
"How much risk do you believe each of the following poses to the safety or health of people in our society?"
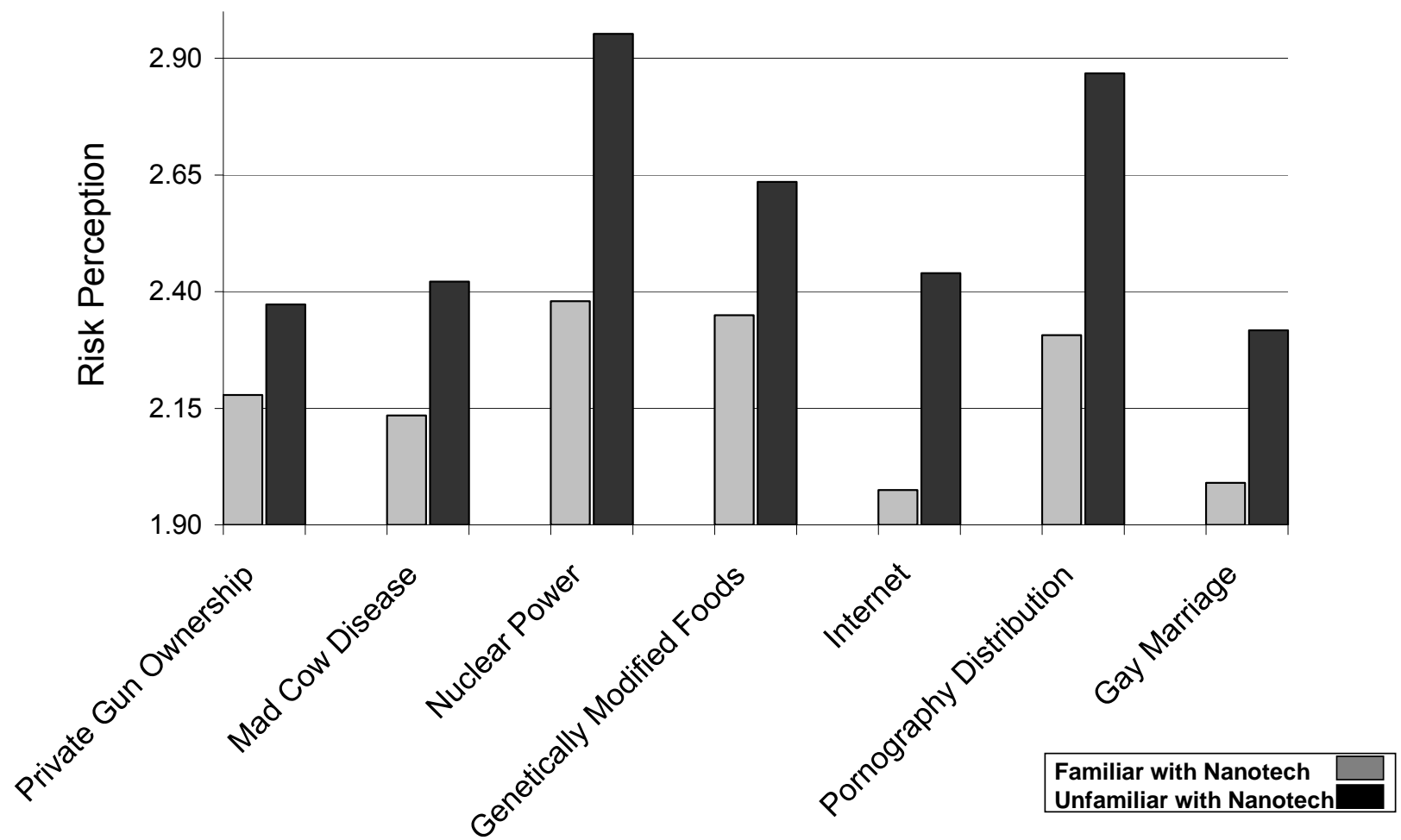

$N \approx 1,500$. Mean risk perceptions for each group measured on 4-pt scale. Difference in means for all comparisons significant $p<.05$.

\section{Figure 2. Societal Risk Perceptions of Persons Familiar and Unfamiliar with Nanotech-} nology

This conclusion in itself casts doubt on the rational enlightenment hypothesis. If familiarity with nanotechnology does not cause societal-risk insensitivity generally, why assume that such familiarity causes lack of concern about nanotechnology risks in particular? Why not infer, instead, that the latter correlation, like the former, is spurious-that is, that some influence causes people both not to worry about nanotechnology and to want to learn about it? If that is so, there would be no more reason to believe that exposing individuals unfamiliar with nanotechnology to information about it will make them less concerned with nanotechnology than there is to think that exposing them to that same information will make them less concerned with, say, mad cow disease. 


\subsection{Impact of Information Exposure}

The impact of information on persons unfamiliar with nanotechnology was, of course, the focus of the between-subjects information experiment. Comparison of the risk perceptions of subjects in the no-information and information treatments is reported in Table 2 and Figure 3 and Figure 5).

\begin{tabular}{|c|c|c|c|}
\hline \multirow[b]{3}{*}{ Overall } & \multicolumn{3}{|c|}{ Mean Risk/Benefit Perception } \\
\hline & No Information & Information-Exposed & Significance \\
\hline & 2.66 & 2.65 & - \\
\hline Men & 2.81 & 2.91 & \\
\hline Women & 2.50 & 2.45 & \\
\hline Whites & 2.67 & 2.76 & $a^{* *}$ \\
\hline Blacks & 2.32 & 2.02 & $a^{* *}$ \\
\hline Republicans & 2.66 & 2.74 & \\
\hline Democrats & 2.66 & 2.62 & \\
\hline Liberals & 2.78 & 2.62 & $\mathrm{~b}^{* *}$ \\
\hline Conservatives & 2.66 & 2.71 & $\mathrm{~b}^{* *}$ \\
\hline Hierarchs & 2.64 & 2.72 & $\mathrm{c}^{*}$ \\
\hline Egalitarians & 2.67 & 2.58 & $\mathrm{c}^{*}$ \\
\hline Individualists & 2.62 & 2.73 & $\mathrm{~d}^{* *}$ \\
\hline Communitarians & 2.70 & 2.54 & $\mathrm{~d}^{* *}$ \\
\hline Hierarchal Individualists & 2.65 & 2.81 & $\mathrm{e}^{* *}, \mathrm{f}^{* *}$ \\
\hline Hierarchical Communitarians & 2.63 & 2.47 & $\mathrm{e}^{* *}$ \\
\hline Egalitarian Individualists & 2.56 & 2.60 & \\
\hline Egalitarian Communitarians & 2.73 & 2.57 & $f^{* *}$ \\
\hline Not Familiar & 3.23 & 3.11 & \\
\hline Familiar & 2.51 & 2.51 & \\
\hline
\end{tabular}

\section{Table 2. Risk/Benefit Perception by Group Across Experimental Conditions}

The results were strongly consistent with the cultural cognition hypothesis. Whereas Hierarchs, Egalitarians, Individualists and Communitarians all had roughly comparable mean evaluations in the no-information condition, these types significantly diverged relative to one another in expected directions-Hierarchs and Individualists toward benefit, and Egalitarians and Communitarians toward risk-in the information-exposure condition (Figure $3)$. 


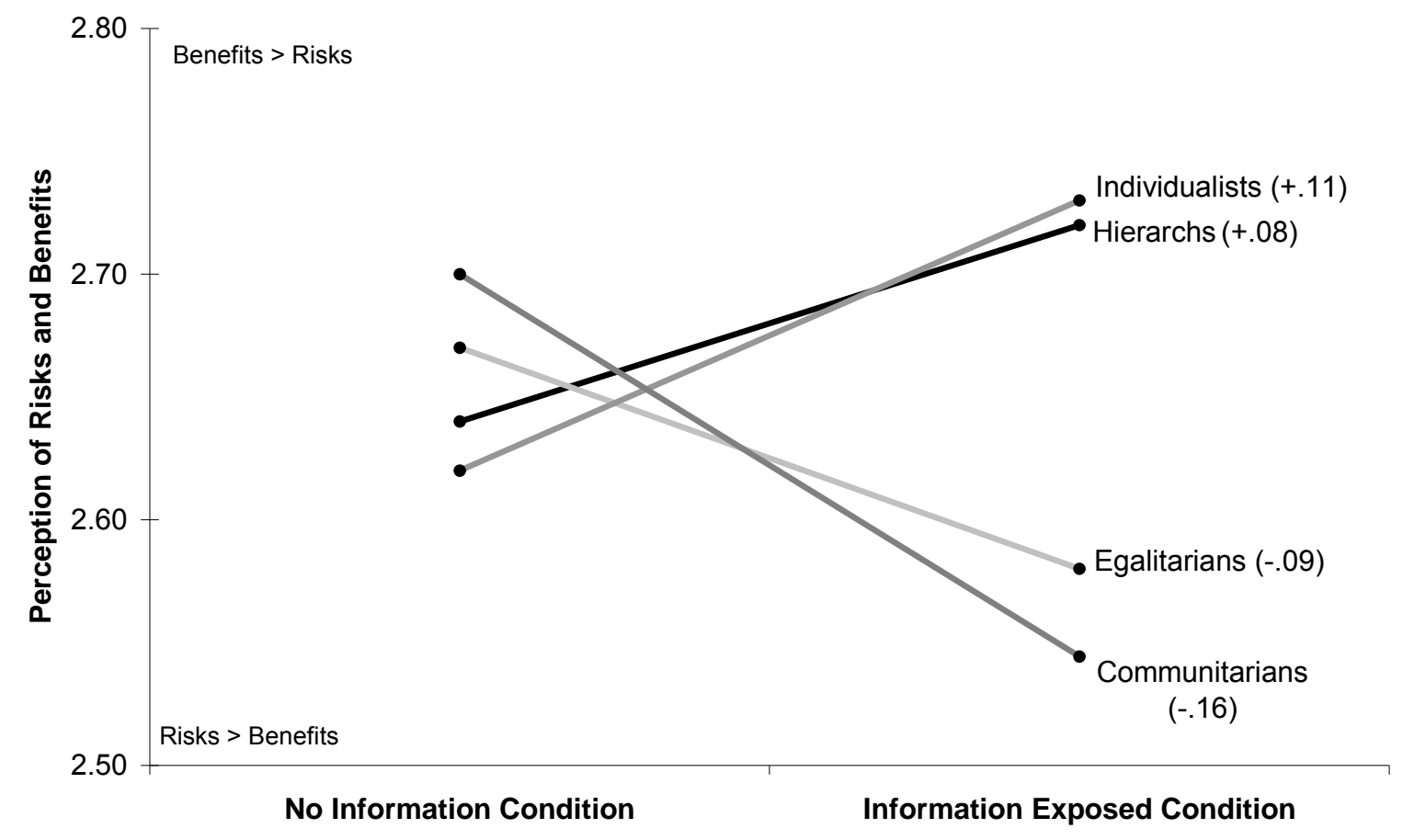

Figure 3. Impact of Information Exposure on Subjects Defined by Cultural Worldviews

We saw a similar effect across subjects divided into the four cultural types formed by the overlap of the Hierarchy-Egalitarian and IndividualismCommunitarian worldview dimensions. Although not significantly different from each other in the no-information condition, Egalitarian Communitarians and Hierarchical Individualists assumed their characteristically risk-sensitive and risk-skeptical positions, respectively, in the information-exposure condition (Table 2, Figure 4). Hierarchical Communitarians and Hierarchical Individualists also polarized, suggesting that a combination of hierarchical and individualistic views most powerfully disposed subjects to be receptive to the benefits of nanotechnology. 


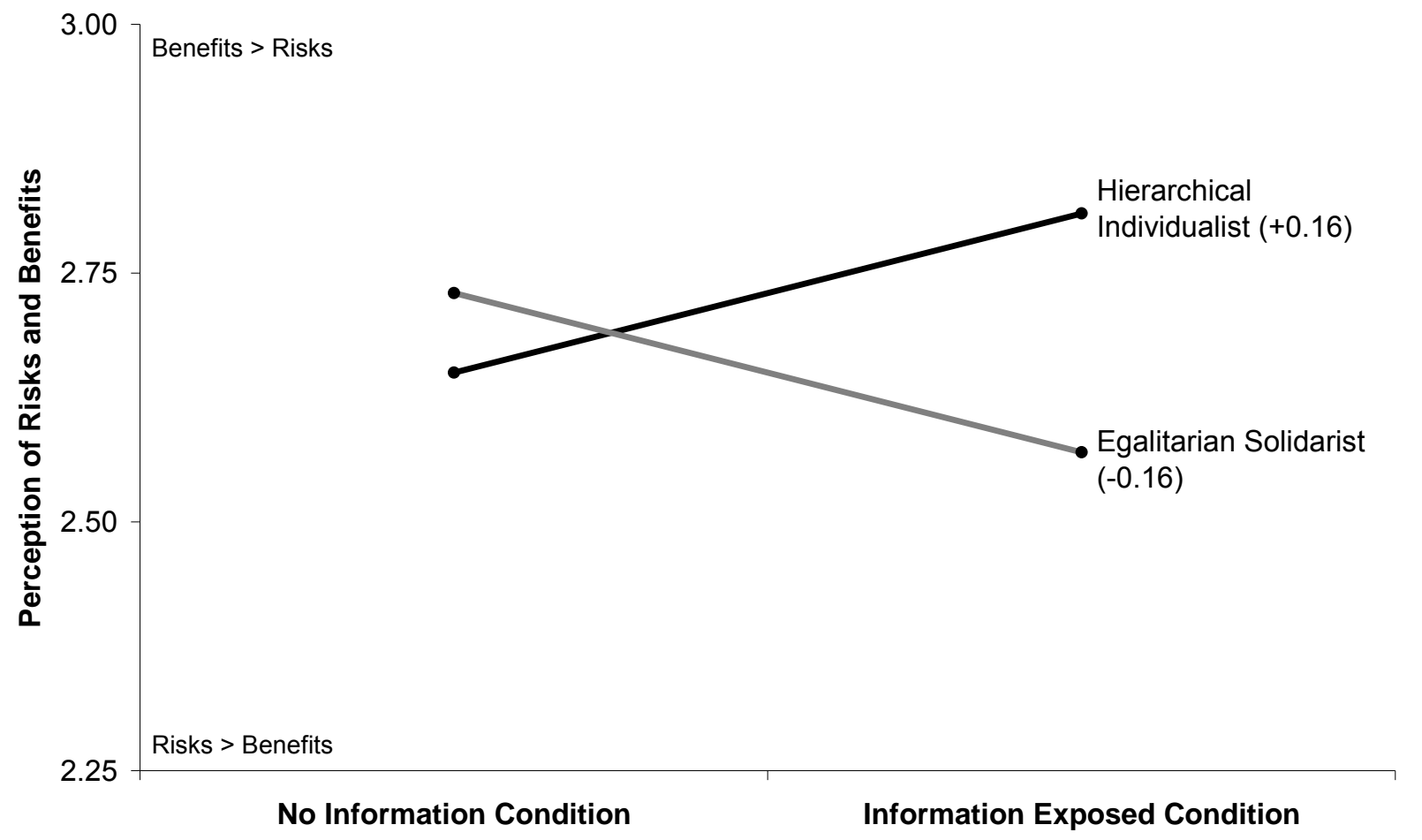

Figure 4. Effect of Information Exposure on Subjects Defined by Combinations of Cultural Worldviews

Subjects also polarized along other lines. Thus, the gap between whites and African-Americans widened in the information-exposure condition. Liberals also adopted a more risk-sensitive stance, and conservatives a less risksensitive one. Because these characteristics tend to correlate with cultural worldviews (Kahan \& Braman 2006), polarization along these lines is also consistent with the cultural cognition hypothesis.

The results also permit evaluation of the rational enlightenment hypothesis. That hypothesis implied that subjects previously unfamiliar with nanotechnology would form a more positive view in the information-exposure condition than in the no-information condition; it implied as well that the gap between previously unfamiliar and previously familiar subjects would be smaller in the information-exposure condition.

Neither of these effects was observed. On net, individuals who were not familiar with nanotechnology before the experiment did not move in the direction of those where were familiar in the information condition. There was no significant net effect on those persons. The reason is that these subjects previ- 
ously unfamiliar reacted diversely to the information-some becoming more concerned about risks and some less-depending on their cultural predispositions.

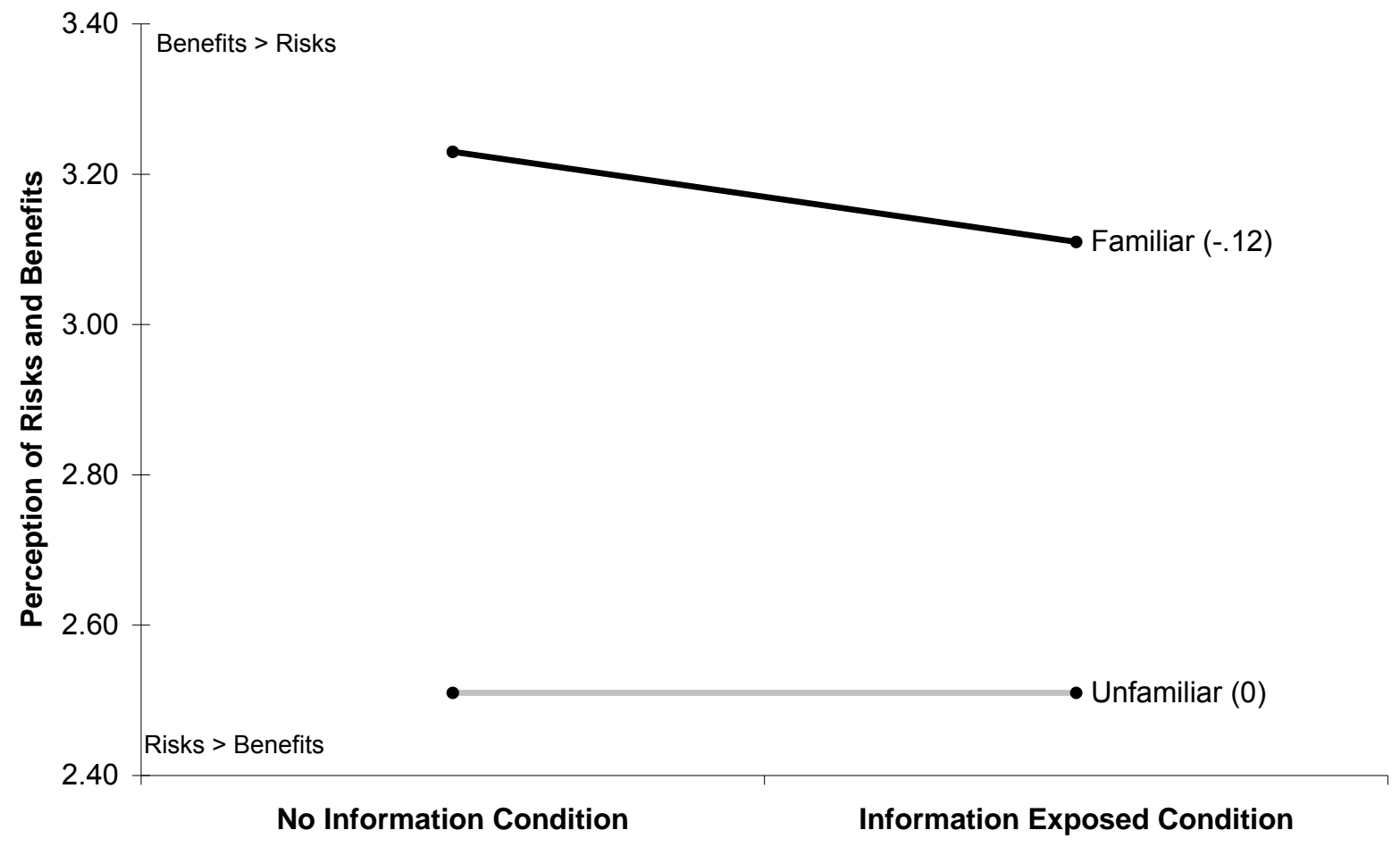

\section{Figure 5. Impact of Information Exposure Across Subjects Defined by Prior Familiarity with Nanotechnology}

This finding, too, strongly suggests that that the relationship observed between familiarity with nanotechnology and lack of concern about its risks in the general population is spurious. The failure of information exposure to move subjects previously unfamiliar with nanotechnology in a uniformly positive direction is exactly what one would expect if the correlation between previous familiarity and a positive view is the result of a third variable that explains both skepticism toward nanotechnology risks and a disposition to learn about nanotechnology. The only question that remains is what that third variable might be. 


\subsection{Explaining Familiarity with Nanotechnology: The Impact of Gender, Education, and Individualism}

Our results give us a pretty good idea of the answer to that question. Regressing familiarity with nanotechnology on the various individualcharacteristic and cultural measures (Table 3, Model 1) revealed the four strongest predictors to be gender $(O R=0.40, p=.00)$ and race $(O R=.52, p=$ $.00)$, both of which predict less familiarity, and education $(O R=1.38, p=.00)$ and individualism $(O R=1.39, p=.02)$, both which predict more. To illustrate the practical effect of these characteristics, stochastic simulations (King, Tomz $\&$ Wittenberg 2000) can be used to specify the likelihood that a person possessing particular combinations of them would indicate that a person holding one or another combination of them has heard "nothing at all," "just a little," "some," or "a lot" about nanotechnology (Table 4, Figure 6). The analysis shows that the likelihood a person will indicate being familiar with nanotechnology (that is, having heard "some" or "a lot" about it) ranges from $10 \%( \pm 2 \%)$ for a person who is an African-American but in all other respects no different from the population mean to $63 \%$ ( $\pm 3 \%$ ) for a white male who is one standard deviation more individualistic and who has a Ph.D.

This finding extends the results of the study in two respects. First, it helps to explain the existence of the observed correlation between familiarity with nanotechnology and low concern with the riskiness of various activities, including development of nanotechnology (§ 4.1). Individualism tends to predict a low perception risk for behavior that manifest individual initiative and choice. Accordingly, if individualism also disposes persons to learn about nanotechnology, one would expect those who are relatively more familiar with nanotechnology to be insensitive to those types of risks-not because of what they have learned about nanotechnology, obviously, but because they are individualistic in their outlooks. Individualism, in other words, is one of the influences that accounts for the spurious correlation between familiarity with nanotechnology and a perception that its benefits outweigh its risks. 
Logistic Regression Analysis

\begin{tabular}{|c|c|c|}
\hline & Model 1 & Model 2 \\
\hline \multirow[t]{2}{*}{ Female } & 0.40 & 0.41 \\
\hline & $(0.04)$ & $(0.04)$ \\
\hline \multirow[t]{2}{*}{ Black (vs. white) } & 0.52 & 0.51 \\
\hline & $(0.10)$ & $(0.10)$ \\
\hline \multirow[t]{2}{*}{ Other_minority (vs. white) } & 1.02 & 1.02 \\
\hline & $(0.14)$ & $(0.14)$ \\
\hline \multirow[t]{2}{*}{ Education } & 1.38 & 1.36 \\
\hline & $(0.04)$ & $(0.04)$ \\
\hline \multirow[t]{2}{*}{ Age } & 0.99 & 0.99 \\
\hline & $(0.00)$ & $(0.00)$ \\
\hline \multirow[t]{2}{*}{ Household Income } & 0.99 & 0.99 \\
\hline & $(0.01)$ & $(0.01)$ \\
\hline \multirow[t]{2}{*}{ Republican (vs. democrat) } & 1.06 & 1.04 \\
\hline & $(0.13)$ & $(0.12)$ \\
\hline \multirow[t]{2}{*}{ Independent (vs. democrat) } & 0.99 & 0.96 \\
\hline & $(0.22)$ & $(0.21)$ \\
\hline \multirow[t]{2}{*}{ Conservative } & 1.02 & 1.02 \\
\hline & $(0.04)$ & $(0.04)$ \\
\hline \multirow[t]{2}{*}{ Hierarchy-Egalitarianism } & 0.75 & 0.11 \\
\hline & $(0.10)$ & $(0.06)$ \\
\hline \multirow[t]{2}{*}{ Individualism-Communitarianism } & 1.39 & 0.24 \\
\hline & $(0.20)$ & $(0.13)$ \\
\hline \multirow[t]{2}{*}{ Individualism x Hierarchy } & -- & 2.01 \\
\hline & & $(0.40)$ \\
\hline Pseudo R2 & .07 & .07 \\
\hline log likelihood & -1832.88 & -1826.85 \\
\hline Prob $>$ Chi2 & .000 & .000 \\
\hline
\end{tabular}

Table 3. Logistical Regression Analysis of Familiarity with Nanotechnology 
"How much have you heard about nanotechnology before today?"

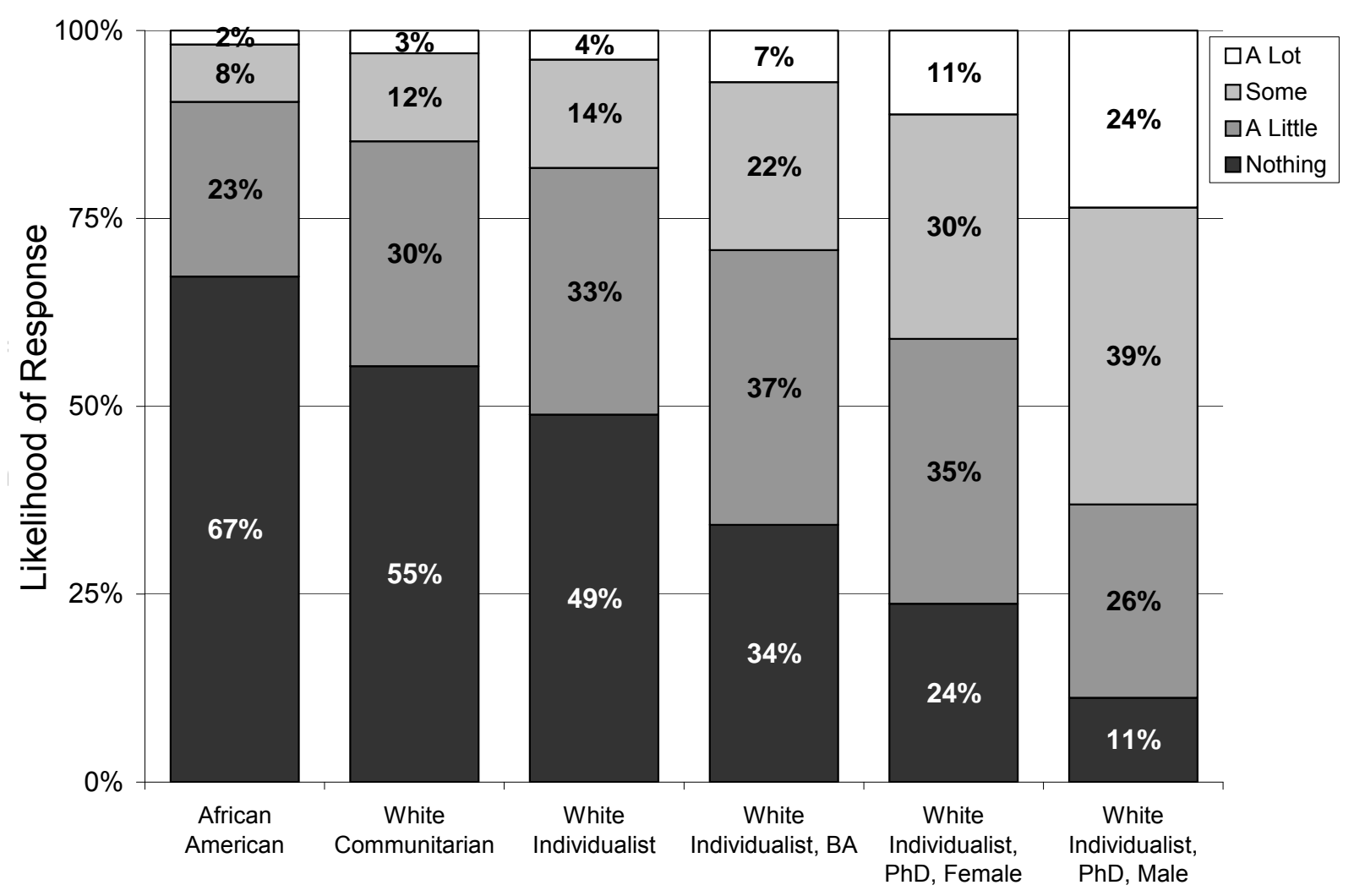

Figure 6. Likelihood of Degree of Familiarity with Nanotechnology

\begin{tabular}{lrrrrrr} 
& $\begin{array}{c}\text { African Ameri- } \\
\text { can }\end{array}$ & $\begin{array}{c}\text { White } \\
\text { Commun. }\end{array}$ & $\begin{array}{c}\text { White } \\
\text { Individ. }\end{array}$ & $\begin{array}{c}\text { White } \\
\text { Individ., BA }\end{array}$ & $\begin{array}{c}\text { White } \\
\text { Individ., PhD, }\end{array}$ & $\begin{array}{c}\text { Female } \\
\text { White Individ., }\end{array}$ \\
\cline { 2 - 6 } Nothing, Male \\
\cline { 2 - 6 } & $67 \% \pm 6 \%)$ & $55 \%( \pm 3 \%)$ & $49 \%( \pm 3 \%)$ & $34 \%( \pm 3 \%)$ & $24 \%( \pm 4 \%)$ & $11 \%( \pm 2 \%)$ \\
A Little & $23 \%( \pm 3 \%)$ & $30 \%( \pm 2 \%)$ & $33 \%( \pm 2 \%)$ & $37 \%( \pm 2 \%)$ & $35 \%( \pm 2 \%)$ & $26 \%( \pm 3 \%)$ \\
Some & $8 \%( \pm 2 \%)$ & $12 \%( \pm 1 \%)$ & $14 \%( \pm 1 \%)$ & $22 \%( \pm 2 \%)$ & $30 \%( \pm 4 \%)$ & $39 \%( \pm 3 \%)$ \\
A Lot & $2 \%( \pm 0 \%)$ & $3 \%( \pm 1 \%)$ & $4 \%( \pm 1 \%)$ & $7 \%( \pm 1 \%)$ & $11 \%( \pm 3 \%)$ & $24 \%( \pm 5 \%)$ \\
\hline
\end{tabular}

$N=1,785$. Parentheticals reflect margins of error at $p=.05$

\section{Table 4. Likelihood of Degree of Familiarity with Nanotechnology}

Second, the finding that individualism is one of the influences that explains the disposition to learn about nanotechnology helps to corroborate our interpretation of the information-exposure experiment results. An antiindividualist or communitarian disposition tends to incline persons to be accepting of claims of environmental and technological risks. It is therefore not surprising that relatively communitarian subjects unfamiliar with nanotech- 
nology do not form the positive evaluation of nanotechnology that the predominantly individualistic persons already familiar with it have.

The analysis of who is disposed to become familiar with nanotechnology does display one apparently anomaly. The logistical regression analysis reveals (Table 3, Model 1) that a tendency toward a hierarchical worldview predicts less familiarity with nanotechnology $(O R=0.75, p=.04)$. This appears surprising because hierarchy, like individualism, is associated generally with environmental risk skepticism and, in the information-exposure experiment generated a low assessment of nanotechnology risks. It would appear, then, that hierarchy, unlike individualism, does not play a role in the motivation of persons who are disposed to form a positive view of nanotechnology to learn more about it.

But this inference is at least partially offset by a second regression analysis. In this one (Table 3, Model 2), a variable, Individualism x Hierarchy, is added to measure the interaction of individualism and hierarchy. The odds ratio associated with it is $2.01(p=.00)$. This indicates that for any given person the odds are twice as high that an increasingly hierarchical disposition will be associated with more rather than less familiarity with nanotechnology as that person's worldview becomes progressively more individualistic; likewise, the odds are twice as high that an increasingly individualistic disposition will be associated with more rather than less familiarity with nanotechnology as a person's worldview becomes progressively more hierarchical. Simply put, persons are most disposed to learn about nanotechnology as their worldviews become simultaneously individualistic and hierarchical. This is consistent with the experiment finding that information exposure has a particular pronounced influence on hierarchical individualists.

\section{Conclusion: Implications for the Future of Public Opinion on Nanotechnology}

The findings of this study do not by any means permit the future of nanotechnology to be predicted with complete confidence. But they should help those who want to assure informed development of nanotechnology to identify the steps necessary to make that outcome more likely.

It would be a mistake, this study suggests, to assume that nothing more need be done than to supply people with scientifically sound information. Lack- 
ing the time and expertise to evaluate technical data on risk-particular when it is disputed-individuals naturally tend to credit information selectively depending on its congeniality to their cultural predispositions (Wildavsky 1987). As a result, issues of risk tend to polarize on cultural lines (Kahan et al. 2006).

Our results show that exposure to even a small amount of balanced information about nanotechnology can result in polarization of this sort. Because individuals in the real world are much more likely to select information in a biased fashion that matches their cultural and political dispositions (Mutz \& Martin, 2001), one might anticipate even more extreme polarization outside the lab. Nanotechnology, on this view, could go the route of nuclear power and other controversial technologies, becoming a focal point of culturally infused political conflict.

At the same time, there is nothing in this study to suggest that such a future is inevitable. It seems unlikely that the tendency of persons to filter information through emotion and values can be neutralized. But the tendency of these information-processing mechanisms to divide people almost certainly can be. Social psychology, moreover, is making important advances in identifying techniques for framing information on controversial issues of policy in a manner that makes it possible for persons of diverse values to derive the same factual information from it (Cohen, Aronson \& Steele 2000). With further study, it is likely that these techniques can be used to guide risk communication and thus enhance democratic deliberations about risk-regulation policy-on nanotechnology (Scheufle 2006) and on other issues (Cultural Cognition Project 2007b).

The practical lesson of this study, then, is that those who favor informed public deliberations over nanotechnology should be neither sanguine nor bleak. Instead they should be psychologically realistic. And if they are, they will see the urgent need for additional efforts to develop risk communication strategies that make it possible for culturally diverse citizens to converge on policies that promote their common interests. 


\section{Bibliography}

Cobb, M. D., \& Macoubrie, J. (2004). Public perceptions about nanotechnology: Risks, benefits and trust. Journal of Nanoparticle Research, 6, 395-404.

Cohen, G. L., Aronson, J., \& Steele, C. M. (2000). When Beliefs Yield to Evidence: Reducing Biased Evaluation by Affirming the Self. Personality and Social Psychology Bulletin, 26(9), 1151-1164.

Cultural Cognition Project at Yale Law School (2007a). Nanotechnology Risk Perceptions: The Influence of Affect and Values, http://www.nanotechproject.org/process/files/2710/164_nanotechriskp erceptions_dankahan.pdf.

Cultural Cognition Project at Yale Law School (2007b). The Second National Risk and Culture Study: Making Sense of-and Making Progress In-the American Culture War of Fact, http://papers.ssrn.com/sol3/papers.cfm?abstract_id=1017189.

Curall, S. C., King, E. B., Lane, N., Madera, J., \& Turner, S. (2006, Dec. 2006). What Drives Public Acceptance of Nanotechnology? Nature Nanotechnology, 1, 153-155.

Dake, K. (1991). Orienting Dispositions in the Perception of Risk: An Analysis of Contemporary Worldviews and Cultural Biases. J. Cross-Cultural Psych., 22, 61.

Dennis, J. M., Li, R., \& Chatt, C. (2004). Benchmarking Knowledge Networks' Web-Enabled Panel Survey of Selected GSS Questions Against GSS InPerson Interviews, http://www.knowledgenetworks.com/ganp/docs/GSS\%202002\%20DK\% 20Rates\%20on\%20KN\%20Pane1\%20v3.pdf.

DiMaggio, P. (1997). Culture and cognition. Annual Review of Sociology, 23, 263-287.

Douglas, M. (1970). Natural symbols: explorations in cosmology. London,: Barrie \& Rockliff the Cresset P.

Ellis, R., \& Thompson, M. (1997). Seeing Green: Cultural Biases and Environmental Preference. In R. Ellis \& M. Thompson (Eds.), Culture matters : essays in honor of Aaron Wildausky (pp. 169-188). Boulder, Colo.: Westview Press.

Gyawali, D (1999). Institutional Forces Behind Water Conflict in the Ganga Plains. GeoJournal 47: 443-452. 
Hart Research Associates. (2006). Report Findings, http://www.nanotechproject.org/file_download/files/HartReport.pdf.

Hart Research Associates. (2007). Awareness of and Attitudes Toward Nanotechnology and Federal Regulatory Agencies, http://www.nanotechproject.org/process/files/5888/hart_nanopoll_200 7.pdf

Jenkins-Smith, Hank C. (2001). Modeling Stigma: An Empirical Analysis of Nuclear Waste Images of Nevada, in Risk, Media, and Stigma: Understanding Public Challenges to Modern Science and Technology (P. S. James Flynn, and Howard Kunreuther ed.).

Kahan, D. M., Braman, D., Gastil, J., Slovic, P., \& Mertz, C. K. (2007). Culture and Identity-Protective Cognition: Explaining the White-Male Effect in Risk Perception. J. Empirical Legal Studies, 4, 465-505.

Kahan, D. M., Slovic, P., Braman, D., \& Gastil, J. (2006). Fear of Democracy: A Cultural Critique of Sunstein on Risk. Harvard Law Review, 119, 10711109.

King, G., Tomz, M., \& Wittenberg., J. (2000). Making the Most of Statistical Analyses: Improving Interpretation and Presentation. Am. J. Pol. Sci, 44(2), 347-361.

Marris, C., Langford, I. H., \& O'Riordan, T. (1998). A quantitative test of the cultural theory of risk perceptions: Comparison with the psychometric paradigm. Risk Analysis, 18(5), 635-647.

Peters, E. M., Burraston, B., \& Mertz, C. K. (2004). An Emotion-Based Model of Risk Perception and Stigma Susceptibility: Cognitive Appraisals of Emotion, Affective Reactivity, Worldviews, and Risk Perceptions in the Generation of Technological Stigma. Risk Analysis, 24(5), 1349-1367.

Scheufele, D. A. (2006). Five lessons in nano outreach. Materials Today, 9(5), 64-64.

Scheufele, D. A., \& Lewenstein, B. V. (2005). The public and nanotechnology: How citizens make sense of emerging technologies. Journal of Nanoparticle Research, 7(6), 659-667.

Scheufele, D. A., Corley, E. A., Dunwoody, S., Shih, T.-J., Hillback, E., \& Guston, D. H. (2007). Scientists worry about some risks more than the public. Nat Nano, 2(12), 732-734.

Slovic, P. (2000). The Perception of Risk. London ; Sterling, VA: Earthscan Publications. 
Steg, L., \& Sievers, I. (2000). Cultural theory and individual perceptions of environmental risks. Environment and Behavior, 32(2), 250-269.

Sunstein, C. R. (2005). Laws of Fear: Beyond the Precautionary Principle. Cambridge, UK ; New York: Cambridge University Press.

Wildavsky, A., \& Dake, K. (1990). Theories of Risk Perception: Who Fears What and Why? Daedalus, 114, 41.

\section{Appendix A}

\section{Knowledge Networks Panels and Sample for this Study}

\section{Knowledge Networks}

Knowledge Networks (http://www.knowledgenetworks.com/) is a public opinion research firm. It maintains an active respondent pool of some 40,000 persons who are recruited to participate in on-line surveys and experiments administered on behalf of academic and governmental researchers and private businesses. Knowledge Network respondents agree to participate in three to four surveys per month in exchange for Internet access and other forms of compensation. It uses recruitment and sampling methods that assure a diverse sample that is demographically representative of the U.S. population. Numerous studies have concluded that on-line testing of Knowledge Network samples generates results equivalent in their reliability to conventional random-digit-dial surveys (http://www.knowledgenetworks.com/ganp/2005aapor.html), and studies using Knowledge Networks facilities are routinely published in peer-reviewed academic journals (http://www.knowledgenetworks.com/ganp/reviewer-info.html; http://www.knowledgenetworks.com/ganp/docs/KN\%20Bibliog\%205-292007\%20External.pdf).

2. Demographic composition of sample for this study

a. Total number of subjects: 1,862 .

b. Gender: $51 \%$ female, $49 \%$ male.

c. Race: $72 \%$ white, $10.1 \%$ African-American.

d. Average age: 46.4 years. 
e. Median household income: $\$ 35,000$ to $\$ 40,000$.

f. Median education level: Some college. 


\section{Appendix B}

\section{Select Experiment Survey Instrument Items}

\section{Cultural Orientation Scales}

Four-point response scale for all items: Strongly Disagree, Disagree, Agree and Strongly Agree.

\section{Individualism-Solidarism Scale} lives.

1. IINTRSTS. The government interferes far too much in our everyday

2. SHARM. Sometimes government needs to make laws that keep people from hurting themselves.

3. IPROTECT. It's not the government's business to try to protect people from themselves. their lives.

4. IPRIVACY. The government should stop telling people how to live

5. SPROTECT. The government should do more to advance society's goals, even if that means limiting the freedom and choices of individuals.

6. SLIMCHOI. Government should put limits on the choices individuals can make so they don't get in the way of what's good for society.

7. SNEEDS. It's society's responsibility to make sure everyone's basic needs are met.

8. INEEDY. It's a mistake to ask society to help every person in need.

9. SRELY. People should be able to rely on the government for help when they need it.

10. IRESPON. Society works best when it lets individuals take responsibility for their own lives without telling them what to do.

11. ITRIES. Our government tries to do too many things for too many people. We should just let people take care of themselves.

12. IFIX. If the government spent less time trying to fix everyone's problems, we'd all be a lot better off.

13. IENJOY. People who are successful in business have a right to enjoy their wealth as they see fit.

14. IMKT. Free markets-not government programs-are the best way to supply people with the things they need.

15. IPROFIT. Private profit is the main motive for hard work. 
16. IGOVWAST. Government regulations are almost always a waste of everyone's time and money.

\section{Hierarchy-Egalitarianism Scale}

1. HEQUAL. We have gone too far in pushing equal rights in this country.

2. HREVDIS1. Nowadays it seems like there is just as much discrimination against whites as there is against blacks.

3. EWEALTH. Our society would be better off if the distribution of wealth was more equal.

4. ERADEQ. We need to dramatically reduce inequalities between the rich and the poor, whites and people of color, and men and women.

5. EDISCRIM. Discrimination against minorities is still a very serious problem in our society.

6. HREVDIS2. It seems like blacks, women, homosexuals and other groups don't want equal rights, they want special rights just for them.

7. HCHEATS. It seems like the criminals and welfare cheats get all the breaks, while the average citizen picks up the tab.

8. EDIVERS. It's old-fashioned and wrong to think that one culture's set of values is better than any other culture's way of seeing the world.

9. HWMNRTS. The women's rights movement has gone too far.

10. ESEXIST. We live in a sexist society that that is fundamentally set up to discriminate against women.

11. HTRADFAM. A lot of problems in our society today come from the decline in the traditional family, where the man works and the woman stays home.

12. HFEMININ. Society as a whole has become too soft and feminine.

13. EROUGH. Parents should encourage young boys to be more sensitive and less rough and tough.

\section{Other Risk Perception Items}

How much risk do you believe each of the following poses to the safety or health of people in our society? [Almost No Risk, Slight Risk, Moderate Risk, High Risk]

GUNOWN. Private Gun Ownership

COW. Mad Cow Disease 
NUKEPOW. Nuclear Power

PORNO. Pornography

GENFOOD. Genetically Modified Food

INTERNET. The Internet

ANTIABORTION. Legal Restrictions on Abortion

GAYMAR. Gay Marriage

\section{Nanotechnology Items}

General Introduction and knowledge item

INTRO9. Now we would like to know what you think about nanotechnology. Nanotechnology is the ability to measure, see, predict and make things on the extremely small scale of atoms and molecules. Materials created with nanotechnology can often be made to exhibit very different physical, chemical, and biological properties than their normal size counterparts.

NANOKNOW. How much have you heard about nanotechnology before today? [Nothing at All, Just a Little, Some, A Lot]

\section{Information Manipulation}

The potential benefits of nanotechnology include the use of nanomaterials in products to make them stronger, lighter and more effective. Some examples are food containers that kill bacteria, stain-resistant clothing, high performance sporting goods, faster, smaller computers, and more effective skincare products and sunscreens. Nanotechnology also has the potential to provide new and better ways to treat disease, clean up the environment, enhance national security, and provide cheaper energy.

While there has not been conclusive research on the potential risks of nanotechnology, there are concerns that some of the same properties that make nanomaterials useful might make them harmful. It is thought that some nanomaterials may be harmful to humans if they are breathed in and might cause harm to the environment. There are also concerns that invisible, nanotechnology-based monitoring devices could pose a threat to national security and personal privacy.

Risk/Benefit Item

NANORISK. Do you think

(1) the risks of nanotechnology will greatly outweigh its benefits

(2) the risks of nanotechnology will slightly outweigh its benefits 
(3) the benefits of nanotechnology will slightly outweigh its risks

(4) the benefits of nanotechnology will greatly outweigh its risks 